\title{
Rituales hispano-mexicanos del Apóstol Santiago
}

\author{
¡Viva la religión que es apostólica Romana \\ que profesamos aquí y en toda la nación mexicana! \\ ¡Viva la cabeza visible y el padre eterno! \\ ¡Viva esta compaña que hemos vencido!
}

(Apóstol Santiago, en Ixtapalapa, México D.F.)

Entre las numerosísimas representaciones rituales que tienen lugar en las fiestas tradicionales mexicanas, hay un personaje con tal protagonismo que destaca sobre los demás: Santiago Apóstol, el Hijo del Trueno, patrono de los españoles. Parece extraño que los actuales indígenas sigan rindiendo un esplendoroso culto al símbolo empleado por los conquistadores hispanos para fortalecer su dominio sobre los antiguos mexicas, y en este trabajo me aproximaré a este fenómeno cultural, centrándome en uno de los rituales más enigmáticos de los que se siguen celebrando: los Tastoanes.

\section{Presencia del apóstol Santiago en México}

Al igual que en ciertas fases de la Reconquista de la Península Ibérica las huestes cristianas atribuyeron sus victorias a la ayuda milagrosa de uno de los más cercanos discípulos de Jesucristo, en la conquista del Nuevo Mundo también resonó la invocación al santo para favorecer el triunfo de las tropas bajo el signo de la Cruz. Hasta tal punto fue enarbolado su estandarte, que «creían los indios que Santiago armado y a caballo era el Dios

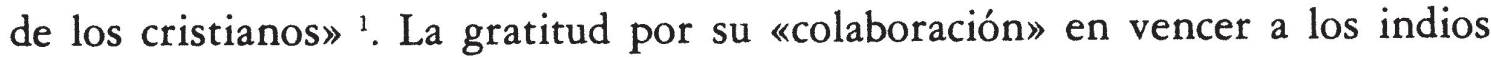
idólatras se le demostró al colocar bajo su patrocinio gran parte de las nuevas poblaciones erigidas por los españoles y sus aliados. Así, son 83 las fundaciones con su nombre en México, mientras que en Perú ascienden a 23 y

1 José Antonio GAY, Historia de Oaxaca (México: Porrúa, 1986), p. 162, citando a Remesal. La imagen de Santiago iba en altares portátiles de campaña. 
en Guatemala son 6, incluyendo la capital ${ }^{2}$. Un curioso caso de desdoblamiento de personalidad se tiene en Santiago Yaunahuac (Puebla), donde los vecinos veneran tres diferentes estatuas de su santo protector, conociéndolas como San Jacobito, Santiago Español y Santiago Morito ${ }^{3}$, lo que se presta a un jugoso análisis conceptual.

Es de suponer que un patrocinio tan extendido diera lugar a múltiples variantes de rituales festivos, ya que incluso las autoridades eclesiásticas mostraron su alarma. Entre las primeras intervenciones de los reformistas de la Ilustración contra los excesos paganos en las fiestas religiosas, se cuenta la del Arzobispo de México Francisco de Lorenzana, quien en 1769 ordenó

que en lo adelante no se hagan ni permitan Nescuitiles [obras de teatro], representaciones en vivo de la Pasión de Cristo Nuestro Redentor, palo del volador, danzas de Santiaguitos, ni otros bailes supersticiosos, en idioma alguno, aunque sea en nuestro vulgar castellano, $[\ldots]$ ya [que] en estos tiempos en que han corrido dos siglos y medio, es disonante y obsta la [...] prohibición por los gravísimos pecados, imponderables inconsecuencias, irrisiones, vanas observancias, irreverencias, supersticiones, y demás justas causas que lo motivaron ${ }^{4}$.

A pesar de esta severa prohibición, en la que se mezcla la danza de Santiago con otros rituales irreverentes y supersticiosos, no se la pudo suprimir del repertorio de los rituales festivos indígenas en los que ya estaba integrada, y de los que hoy día sigue siendo elemento central, como se verá en los siguientes casos.

A veces se suelen confundir las Danzas de Carlomagno y la de los Santiagueros, con su duelo de machetes (San Pedro el Alto, Guerrero), aunque el modelo representativo más extendido es una variante de las danzas o funciones teatrales de Moros y Cristianos, que se llaman genéricamente Santiagos, bastante difundidas por la zona central de México.

El argumento de estas representaciones se puede resumir así:

El Apóstol Santiago envía a su Embajador a Jerusalem a pedir al rey musulmán Pilatos se rinda como vasallo y pague tributo. El embajador, después de muchas dificultades y palabrería, logra hablar con Pilatos, pero éste no acepta la demanda y reta a Santiago a la guerra. Se desafían moros y cristianos. Pilatos envía a Tiberio

2 Gisela Beutler, La Historia de Fernando y Alamar (Stuttgart: F. Steiner Verlag, 1984), p. 15.

3 Robert RICARD, «Les fêtes de "Moros y Cristianos" au Mexique (Addition)», Journal de la Société des Americanistes, XXIV (1932), pp. 287-288.

4 Eduardo Merlo, Apuntes sobre las danzas de Cuetzalan (Puebla: Proarte, 1986), p. 13 , cit. a Lorenzana, 1770 , pp. 68 y ss. 
a retar a Santiago. Después de una lucha feroz, en la cual Santiago resulta el vencedor, se convierte Pilatos y es bautizado 5 .

El principal contrincante de Santiago (quien parece ser el rey de Roma, con Caín como su embajador) es el rey o presidente Pilatos, acompañado por el Alchareo (hijo de Herodes) y Tiberio como el general y embajador del bando moro-pagano. Por el importante papel jugado por el contemporáneo de Santiago que intervino en la muerte de Cristo, en muchos sitios se conoce la danza como los Pilatos, mientras que en otros es su ayudante Alchareo quien proporciona el nombre; los Alquileos. Es interesante notar que la palabra «pilato» se entronca con la voz nahuatl «pilatone», que significa «señor de alcurnia», y que entre los totonacas de Veracruz aparece como rey de los olmecas, con su rodela y lanza.

En la sierra norte de Puebla, en Cuetzalan, la cuadrilla de «santiagos» de cada localidad está compuesta por una quincena de danzantes, que por manda o promesa se comprometen a cumplir durante siete años consecutivos con bastantes obligaciones rituales. Es tan largo el desarrollo íntegro de la representación, que la deben hacer por partes a lo largo de las diversas festividades del año, a fin de culminarla por Año Nuevo. Quien organiza y dirige la cuadrilla es el Teniente, y al texto le llaman «testamento». Suelen ir enmascarados los danzantes, acompañados por la música de una flauta de carrizo y un tambor. Santiago Caballero se distingue por su caballito blanco de madera colocado a la cintura, y en una comunidad le llaman «Telpulzintle Emperador», correspondiendo la palabra nahuatl a uno de los nombres con los que se identifica al dios Tezcaltlipoca ${ }^{6}$. Como prueba del sincretismo practicado, véase la súplica que el Teniente dirige al santo patrono de su pueblo, Cuauhtapanaloyan:

Señor Santiago Caballero. / ahora si es derecho / nuestro señor y rey, / nuestro señor ahora sí es derecho. / Nuestros señores caballeros, / nuestros señores Pilatos, / nuestros señores reyes, / ahora mi pobre Cayintzin, / los buscamos mis señores, / nuestros reyes coronados, / Señor Santiago Caballero, / nuestro pobre Cayintzin, / nos entregamos a tí, / cuando te buscamos, / a tí te buscamos / ... ${ }^{7}$.

Por mi parte, en la cercana San Miguel Tzinacapan, obtuve la siguiente información sobre la Danza de Pilatos, de un señor que había sido danzante

5 Fernando Horcasitas, «Versos de la Danza de Santiagos de Taxco, Guerrero», Anales de Antropología (1980), p. 101.

6 E. MERLo, op. cit., p. 53. También significa «el jovencito».

7 Ibidem, p. 61. Transmitido oralmente, el texto nahuatl tiene añadidas muchas palabras castellanas y es incomprensible. 
durante muchos años: «Acherugo el mero mayor. Santiago tiene corona. Pilatos tiene un machete de palo. Diablos llevan Pilato, se mata el caballero de Pilato y se acaba la fiesta. Los ángeles defienden su reino.»

El motivo inspirador del ciclo de combates rituales entre Santiago y Pilatos parece encontrarse en una novela escrita en valenciano por San Pedro Pascal, mercedario que fue obispo de Jaén y capturado por los nazaríes fue decapitado en Granada en el año 1300. Titulada Destruccio de Hierusalem, ofreció el argumento de la obra teatral escrita en nahuatl Destrucción de Jerusalem, posiblemente del siglo XVI, donde el bando cristiano está encabezado por el Emperador Vespasiano (por corrupción, a veces a Santiago se le llama «caballero barbeciano») y su hijo Tito, mientras que Pilatos es gobernador de los judíos, y Arquelao su rey ${ }^{8}$.

Hay una interesantísima versión de la Danza de Santiagos en Almolonga (Guerrero), donde Santiago, Vespasiano y Tito se enfrentan contra el presidente Pilatos, Sultán y Tiberio, a quienes apoya su dios Mahoma, estrafalario personaje disfrazado de mujer que monta un burro y se atreve a retar al Apóstol: «Santiago, yo soy tu rey y Pilatos mi segundo, / aquí te haces a mi ley, o te despachamos al otro mundo», y mientras se efectúa el combate a machetes, el Mahoma improvisa coplas eróticas del estilo de: «Las muchachas de este rumbo / son como las lomas, / ellas se ponen las naguas / sabiendo que las traen pelonas.» Tras la batalla por la túnica del Señor, Pilatos se rinde ante Santiago con la frase: «iVenciste, español, venciste!», fugándose luego encadenado mientras los de su bando se convierten ?. Un Mahoma burlesco casi idéntico aún suele aparecer en representaciones en el interior de la Alpujarra de Granada (Mecina-Tedel, Cojáyar), y es heredero directo de la primera función hispánica de Moros y Cristianos de la que se conservan íntegros los parlamentos, efectuada en la Jaén fronteriza en 1463 para festejar con un juego de cañas y unas «burlas moriscas» el feliz desenlace de una incursión militar dentro del reino musulmán de Granada ${ }^{10}$.

A menudo, el personaje del Apóstol viste un elegante traje charro (como también sucede en muchas de sus representaciones iconográficas), y en la Danza del Señor o de las Sonajas, de El Naranjo (Michoacan), Santiago vence a los infieles para liberar a las dos niñas o Malinches con las que termina bailando. Otra curiosa variante es la Danza de los Moros Cabezones de Chipalcingo (Guerrero), donde los infieles simulan apoderarse del Niño-Dios,

8 R. RicaRD, op. cit., p. 289. El primero en destacar la conexión fue el erudito mexicano Paso y Troncoso.

9 Descripción publicada en México Indígena (INI, junio de 1990).

10 En la crónica anónima Hechos del condestable Miguel Lucas de Iranzo, Ed. J. DE LA Mata (Madrid: Espasa-Calpe, 1940), pp. 98-100. 
acudiendo a su rescate el Apóstol, quien se lo lleva montado en su caballito de madera, y la parecida Danza de los Santiagueros de Tetelcingo (Morelos), en la que los dos Señores Santiaguito junto con sus caballeros luchan contra los judíos para liberar a Jesús, que éstos mantienen prisionero. En este ritual nahua, la personificación del papel del Santiago exige una serie de cuidados especiales hacia el rudimentario caballo de madera que es su mayor atributo:

Al serle entregado el caballito de madera, cada uno de los elegidos se compromete a "alimentarlo" durante los dos años que durará el cargo, para lo cual se preparan dos jícaras; una de ellas destinada a contener agua y la otra maíz. Ambas jícaras son colocadas en un altar doméstico especialmente preparado, al cual se amarra el caballo. Cada quince días se le debe cambiar el contenido de las jícaras, que se acumula para ser presentado y ofrecido al mayordomo al cumplirse el año. De esta manera se prueba que la familia poseedora cumplió adecuadamente con la tarea de cuidar al preciado caballito, al mismo tiempo que se proporciona una ayuda para los gastos a los que tendrá que hacer frente el mayordomo durante la realización de la fiesta ${ }^{11}$.

Otras muestras de la importancia ritual que puede tener el «caballito» fingido se tienen en Jocotán (Jalisco), donde se considera que «Santiago y su caballo son hermanos» ${ }^{12}$, y en el ya citado municipio de Cuetzalan, donde también hay que alimentar al caballito con agua y maíz y puede atraer males sobre la comunidad si no se cumple con la representación íntegra de la función.

Otra intervención, esta vez real, de los caballos en una fiesta patronal en honor de Santiago se encuentra entre los coras de Chuízete (Nayarit), que compiten entre sí por arrebatar el gallo que uno de ellos lleva en la mano. Al día siguiente, son las mujeres las que cabalgan para luchar por la posesión de una gallina ${ }^{13}$. En cuanto al caballito de madera, en el carnaval de Papalotla (Tlaxcala) son unos «vaqueros» los que simulan montarlo y entablar carreras contra otros jinetes, también de aspecto serio.

\section{Rituales DE SANTIAGO EN ESPaÑa}

En España han corrido ríos de tinta sobre la realidad o leyenda del que se considera el sepulcro más occidental de un apóstol de Cristo. En un monte

11 Alicia BARABAS y Miguel BARTOLOME, Ritual y etnicidad entre los nabuas de Morelos (Morelos: INAH, 1981), p. 31.

12 Encuesta a don José Ascensión Gómez, 73 años, quien salió de Santiago en 1958 y participa todos los años como tastoan.

13 Pedro Castillo, Calendario folklórico de las fiestas en Nayarit (Tepic, 1979), en fiestas del 25 de julio. 
sagrado cercano a Finisterre había un cementerio precristiano, donde en el año 811, de modo milagroso, se descubren los huesos de Santiago. Durante el siguiente siglo se le rinde un gran culto, con su confirmación en la batalla de Simancas (año 939) en la que los leoneses-gallegos se alzaron contra el tributo que les exigía Abderramán III, venciéndole con la supuesta ayuda celestial de Santiago, que se convirtió en su patrono bélico. Para conseguir este honor tuvo que desbancar a San Millán, el eremita riojano que los castellanos habían convertido en su patrono en el 935. Las implacables razzias emprendidas por Almanzor a fines del siglo $\mathrm{X}$ consiguieron asestar un duro golpe a ambos símbolos guerreros, ya que fueron quemados los templos que albergaban sus restos.

Como respuesta al desánimo causado por la espada de Almanzor, en el 5. Concilio de Toledo (1007) se trató sobre la fiesta del patrón de las Españas, Santiago, proponiéndose o aumentar su solemnidad o resucitarla en caso de que cesara ${ }^{14}$. Muy poco después, en el 1017, los nobles castellanoleoneses fundaron una congregación nombrada Orden de la Caballería de Santiago, con aprobación del rey y los obispos. En el 1174 es confirmada la orden por el Papa, estableciéndose la cabeza de la orden en el convento de Uclés (Cuenca). Entre sus Constituciones se regula el modo en el que deben experimentarse con las armas para la defensa de la Fe, creando la figura de un Visitador que vea si «siempre están bien armados y encabalgados», «y por más ejercicio y honra de las dos festividades del glorioso Apóstol Santiago nuestro Patrón, ordenamos que estos dos días en cada un año hagan los caballeros de la Orden fiestas y ejercicios militares, variando unas veces de una manera y otras veces de otra, como se lo fuésemos ordenando» ${ }^{15}$.

Junto a la Orden Militar de Santiago coexistieron otras cofradías más bien laicas, como la de San Pedro y Santiago de Burgos, que según sus Estatutos de 1415 se abre a «los buenos e hijos de los buenos [...] que mantengan caballo y armas y coberturas para servir y guardar esta cofradía», y que dispone que en la víspera de la fiesta de Santiago «todos los cofrades que tuviesen caballo [celebrarán] bofordamiento, haciendo honra hasta la iglesia de Santiago» ${ }^{16}$, siendo la «boforda» una especie de torneo o juego bélico.

14 P. Antonio DE Quintanadueñas, Santos de la Imperial ciudad de Toledo (Madrid, 1651), p. 73.

15 Francisco DE OCAMPO, Obligaciones de los cavalleros de la Religión de Santiago, s. 1., s. f. (parece escrito a mediados del siglo XVII), Const. I, cap. III-10, p. 48.

16 Francisco Cantera, Alvar Garcia de Santa Maria, cronista de Juan II de Castilla (Madrid, 1951), pp. 32-33. 
A finales del siglo XIII o inicios del siguiente, tuvo lugar un curioso espectáculo con el que los cortesanos del rey Jaime II de Aragón festejaron su santo el día de Santiago (que es el equivalente de Jaime):

Se presentaron a la corte sus criados, vestidos unos de moros y otros de cristianos, y tramando campal pelea en el patio del alcázar del rey, salieron al campo que le cercaba, en donde en un castillo levantado sobre un tablado, se dieron sendas cuchilladas, hasta que apareciendo en un brioso caballo blanco un capitán de la guardia vestido de San Jaime, se puso de parte de los cristianos, y acuchillando a los moros, éstos se rindieron de rodillas a sus pies. Que entonces el capitán que hacía de santo tomó de la mano de su escudero una banderita de tela blanca de seda, en que estaba pintada una cruz encarnada [...] y presentándola a los moros, éstos se echaron en tierra y pidieron misericordia y ser recibidos en el gremio de los cristianos [terminando con] un gran divertimiento de baile entre los cristianos y convertidos moros al son de los instrumentos de guerra ${ }^{17}$.

Quizás sea este esquema representativo el que sirvió de modelo para muchos rituales de conquista, con la aparición del propio Santiago incluida. En todo caso, ya en el siglo XIV, se populariza en el sur de Francia (que en gran parte perteneció a los catalanes), el drama provenzal conocido como el Ludus Sancti Jacobi (juego o espectáculo de Santiago), relacionado con los combates simulados que estamos rastreando ${ }^{18}$.

En la última etapa de la Reconquista de las Españas tenemos un ejemplo de la degradación a la que se podía someter un ritual ya tan asentado: «Enrique IV dispuso para la festividad de Santiago, celebrada hasta entonces en Castilla con justas y torneos, una expedición desde Jaén con damas vestidas como soldados, hasta llegar frente a Cambil, donde dispararon arpones», procediéndose luego a un humorístico simulacro de combate, que fue considerado por los caballeros de la Orden de Calatrava como una insultante parodia de sus recientes hazañas militares ${ }^{19}$. Poco después, uno de los favoritos de este monarca castellano, el Condestable Yranzo, en su plaza fuerte de Jaén, celebraba las fiestas de San Juan y del Apóstol Santiago con un juego de cañas y unas «hermosas escaramuzas» entre una parte de sus caballeros en el papel de cristianos y los restantes, fingiendo ser moros, vestidos a la morisca con el adorno de flores y ramas, arremetiéndose y huyendo alternativamente, desde el río hasta regresar a su palacio, donde todos eran convidados a un banquete ${ }^{20}$.

17 Julio Caro Baroja, Las formas complejas de la vida religiosa (Madrid: Akal, 1978), pp. 419-420, cit. a Basilio S. Castellanos.

18 F. HORCASITAS, op. cit., p. 105.

19 Miguel Lafuente, Historia de Granada (Granada, 1846), t. III, p. 303.

20 Op. cit. (10), cap. XV. 
En los siguientes siglos, a menudo se corrían toros el día de la fiesta de Santiago. Para obtener una novedad tenemos que llegar hasta 1755, recién instaurado el régimen borbónico en España, cuando en Valencia se celebra el III Centenario de la canonización de su venerado San Vicente Ferrer, con una procesión general en la que los distintos gremios sacaron sus espectáculos, organizando los curtidores y perailes un torneo a la morisca en el que participaron «un Rey moro con dos hijos [...] doce turcos con Santiago a caballo» ${ }^{21}$ que debían componer una danza.

En cuanto a los datos que nos suministra la etnología comparada, sabemos que en el siglo pasado, el 25 de julio, día del Apóstol, tenía lugar el rito de Las vueltas ecuestres de Santiago, "que se enderezaba a preservar a las caballerías "nobles" de todo mal», ya que el Apóstol Santiago seguía siendo «un santo de los caballeros», a pesar de la pérdida de importancia de su culto en el país ${ }^{22}$. Una celebración ritual totalmente conectada con las mexicanas es la que, hacia 1885, tenía lugar en Cuenca de Campos (Valladolid), en honor de su patrono San Bernardino de Siena, llamada Entradilla de Santiago: los danzantes, al compás del tamboril y la dulzaina o gaita, ejecutaban varias vistosas evoluciones o «lazos», entre los cuales uno de los predilectos era:

que seis de los danzantes, cubiertos con caretas negras para representar a los moros, pelean contra otro compañero que, montado sobre un caballo blanco de madera y cartón y llevando una espada en la mano, simboliza al Apóstol Santiago, el cual ha bajado a pelear contra los moros por haberle invocado el ángel, niño que lleva en la derecha una pequeña cruz, y a quien antes ha desafiado un capitán de moros. Santiago pelea y deja tendidos en el suelo a los moros, que uno tras otro se le van presentando. El Botarga, símbolo del demonio, se dirige al apóstol y después de increparle por haber vencido a los moros, le desafía, pelean y es vencido también. Entonces Santiago, dirigiéndose a los siete que por tierra yacen, les dice que se levanten y adoren la cruz que lleva el ángel, lo que al momento verifican los sarracenos ${ }^{23}$.

Es de destacar que el traje de los danzantes es blanco, con calzón ancho y faldillas, pañuelo de seda a la cabeza y adornados profusamente con esca-

21 ANónimo, Verídica relación de los festivos aplausos con que la muy noble, leal y coronada ciudad de Valencia celebró la procesión general de la Tercera centuria de la canonización de su amado bijo patrón y apóstol San Vicente Ferrer (Valencia, 1755).

22 J. Caro Baroja, op. cit., p. 419, cit. al mismo B. S. Castellanos.

23 Andrés Pérez Garcfa, El libro de Cuenca de Campos (Valladolid, 1886) (reimpreso en 1983), pp. 58-59. Una danza parecida aún se hacía por entonces en la alemana Lübeck, siendo aquí Carlomagno quien combate contra el bufón (narr), personaje similar al botarga, guirria o birria de muchas danzas tradicionales españolas. 
pularios, medallas y cintas de colores. Ya en nuestro siglo, en Benamocarra (Málaga), después de la cosecha, se honraba a su Cristo patrono con una representación de Moros y Cristianos, que en el momento de la batalla decisiva contiene una invocación de los cristianos a Santiago, quien aparece a galope tendido y les conduce a la victoria. En la localidad gallega de Trez (Orense), que perteneció al dominio del conde de Moctezuma (de la poderosa familia de los Mendoza, que suministró altos cargos a la Corona), su patrono Santiago es festejado cada 25 de julio con un combate entre seis moros y seis cristianos, dirigidos por sus respectivos capitanes, que se centra en la posesión de la imagen del santo, que no interviene personalmente. El texto de los parlamentos, relacionado con los aragoneses, tiene un trozo idéntico al de los Moros y Cristianos mexicanos de Zacatecas, cuando el Capitán Moro ofrece comprar al santo a cambio de: "Te prometo dar a Francia / a Holanda, Ingalaterra; / te daré treinta mil turcos / para que guardes tus tierras; / ... / te daré la Casa Santa, / que tanto deseas verla» ${ }^{24}$. Los combates singulares a espada finalizan con la victoria de los cristianos, «abatiendo los moros la cabeza. Cada soldado cristiano da con la espada un golpe en la nuca del adversario», y los moros se convierten y piden perdón al Apóstol.

\section{Los TAstoanes De Jalisco}

Entre los rituales festivos dedicados al Apóstol Santiago, el más intrigante de todos es el que aún se celebra en el estado mexicano de Jalisco, conocido como Los Tastoanes. La voz «tastoan» parece derivarse de la corrupción del mexica «tlatoani»-Señor de siervos, con autoridad de mando. Eran la nobleza hereditaria, equivalente a la voz haitiana «cacique» 25 .

Contamos con una buena descripción de este ritual festivo tal como se efectuaba alrededor de 1888: El día de Santiago, en varias localidades salía la abigarrada turba de los tastoanes, con enormes máscaras de barro o cuero imitando seres humanos grotescos o feroces y animales, con pelucas de cola de res, calzón corto y grandes casacas de colores chillones, llamados algunos con nombre propio: Barrabás, Anás, Satanás, Averrugo. Llevan espada de madera en una mano y en la otra un escudo contra el que la golpean, profiriendo alaridos. Los dirige el Sargento, con kepi calado, que a intervalos

24 Xesus TABoAda, Ritos y creencias gallegas (La Coruña: Sálvora, 2a edic. 1982), p. 66. En cuanto al texto de Zacatecas, fue recopilado en 1952 por Juan B. Rael y editado en 1981 por M. J. Doudoroff.

25 Alberto Santoscoy, La fiesta de los Tastoanes (Estudio etnológico-bistórico) (Guadalajara, 1889), p. 17. 
traza rayas en el suelo con su espada. Por la mañana recorren el pueblo, bebiendo en los bares sin pagar, como prerrogativa suya. También están por las calles el Santiago, a caballo, y sus dos ayudantes, los Moros, con vistoso penacho de plumas. Cuando los dos grupos se encuentran, se intercambian golpes de espada, hasta que Santiago huye y la función prosigue. Por la tarde, los tastoanes salen en marcha triunfal junto con los tres Reyes, con coronas doradas y el rostro teñido (uno de negro, otro blanco y el tercero amarillo), acompañados a veces por un hombre disfrazado de mujer, la Reina. Asentados en un llano, los monarcas ordenan a los danzantes medir el terreno, lo que hacen tendiendo cordeles. Llega luego Santiago a caballo, con capa roja, collar de cascabeles al cuello, traje de vaquero, sombrero con penacho de plumas y machete de hierro. Al verlo, los tastoanes se arrojan contra él, cercándolo, mienras él trata de escapar blandiendo la espada, pero en medio de un griterío incomprensible, lo tiran al suelo, le atan los puños a la espada y lo conducen ante los Reyes-jueces, uno de los cuales simula escribir el interrogatorio en un libro. Después de deliberar, lo sentencian a muerte, ejecutada al momento por los tastoanes, que derraman la sangre de la vejiga que oculta bajo su camisa el sentenciado ${ }^{26}$.

A los cien años de escrita esta descripción, recorrí varios pueblos cercanos a Guadalajara (Jalisco) para obtener información sobre el desarrollo actual de este enigmático ritual festivo. En Jocotán celebran la fiesta de Santiaguito el 8 de septiembre, con la participación de una cicuentena de tastoanes enmascarados, con levita negra y machete de hierro. Santiago es el único que sale a caballo, sin máscara, con sombrero de plumas y un dengue. Es obligación suya dar de comer a los danzantes. Le acompañan unos cinco o seis ayudantes (Sargento, Moro, Perrito rastrero) que tratan de evitar los excesos en las peleas y apaciguar a los borrachos. En la solemne procesión, la imagen del santo es portada por cuatro tastoanes sin máscara. Al regresar al templo comienzan las «jugadas»: se ponen los tastoanes en dos filas, el de la cabeza corre por en medio y toca con su espada la de cada uno, iniciando luego su lucha contra Santiago. Al acabarla, tienen un baile con los tres Reyes, y entran a casa de los cofrades que pagan una invitación al cortejo. Se hacen una docena de combates cada uno de los tres días que dura la fiesta, y los restantes tastoanes tienen que aguardar al siguiente año. Los ayudantes evitan que nadie se salte el orden, ni que se hagan «jugadas» fuera de los emplazamientos acordados. Otro personaje relevante es el Sirinero (corrupción de Cirineo) que reparte bebidas y apunta con su papel los coloquios que mantienen los danzantes en sus duelos singulares con Santiago, que a menudo son de tipo burlesco. El climax de la representación llega cuando el Sirinero

$26 \quad$ Ibidem, pp. 5-12. 
«se pasa al otro lado y vende a Santiago», tendiéndole una emboscada los tastoanes, y después de bajarlo del caballo lo matan, descuartizan y lo tapan con una cobija sobre la que colocan plátanos, manzanas y naranjas. Ahí termina la función el segundo día, saliendo al siguiente otra persona en el papel de Santiago; estando en el suelo, llora el Sirinero y Santiago se levanta «y se sube al caballo a echar carambazos a los tastoanes, que sólo están para recibir. Se hace por gusto, porque es tradición que viene de muy allá» ${ }^{27}$.

Bastante cerca, en San Juan Ocotán, la fiesta del Apóstol Santiago se celebra en su día, el 25 de julio, habiendo salido en 1990 unos sesenta estrafalarios tastoanes y unos veinte ayudantes a caballo. Según un informante del barrio indígena, de 90 años,

Anteriormente había orden. Cada danzante que le tocaba su bailada, salía y peleaba con Santiago y luego tenía sus palabras con los Reyes. Van por manda, incluso señoras, que pedían una cabeza prestada. El «encabezado» hace el gasto, es el que hace de Santo Santiago o el del Caballo, suele ser gente aliviada de una enfermedad, que promete montar a caballo y pagar la danza. Los tastoanes son los judíos que mataron a Cristo, unos soldados de Pilatos, y otros Moros y Capitanes. Los Reyes son Pilatos, Jirafrás y Anás. Cuando salen, se ponen a medir la plaza todo alrededor de la capilla. Es el dinero que se pagó por Cristo. Los ayudantes de Santiago son San Pedro, San Andrés. Antes con leva blanca y pantalón negro. Uno de los apóstoles vendió a Santiago con Herodes, el Sirineo. Matan a Santiago como a Cristo, le ponen una alfombra para arroparlo, para decir que está muerto. Revive Santiago y empieza a cuerear a los judíos. Luego va la gente a pedir curación y Santiago les persigna con la espada y les pega. Si se cree, se puede curar ${ }^{28}$.

Es muy significativa la función curativa ejercida por quien encarna al Apóstol, en ésta y otras localidades: Bajo un árbol permanece de pie, recibiendo la petición de ayuda de los fieles, que uno tras otro se acercan a recibir un golpe de espada (de intensidad relacionada con la gravedad de la dolencia) sobre la parte del cuerpo que tienen mal.

En algunos sitios, las peleas entre los tastoanes y el Santiago son muy recias, ya que adquiere prestigio quien consigue despojar al Santiago de alguna de sus prendas, especialmente el sombrero o la espada, que tiene que rescatar convidando al raptor. Más rudo puede llegar a ser el enfrentamiento ritual llamado Santiagueros, que tiene lugar en Sahaguayo (Michoacán) a mediados de agosto. Aquí salen varios Santiagos a caballo, teniendo que rechazar los ataques de los asistentes que intentan derribarlos, y si algún Santiago cae, quien lo ha tumbado tiene derecho a ocupar su puesto, pagando

27 Informe de don Tereso de Jesús García Reina, ayudante de Santiago desde hace muchos años, recogido en agosto de 1990.

28 Don Julián González Jiménez, entrevistado en agosto de 1990. 
una convidada general. Por otro lado, en San Juan Peyotan (Nayarit), los Moros a caballo persiguen y capturan a su enemigo Santiago.

\section{ANÁLISIS HISTÓRICO-FORMAL}

La fiesta de los Tastoanes se considera originaria de Zacatecas, aunque se ha difundido por el Bajío y es muy popular en Jalisco. En su citado estudio etnológico-histórico, Alberto Santoscoy recuerda que Jalisco era conocido antes de la conquista como Chimalhuacan - lugar de los que usan escudos (chimalli) - y estos objetos, además de su función militar, también servían para danzas guerreras, entrechocándolos con armas ofensivas. En la sublevación de Tenochtitlan, ferozmente reprimida por Pedro de Alvarado, apareció Santiago con su caballo blanco «que mataba tanto con la boca, pies y manos como el caballero con la espada», según Gomara. La primera aparición del Apóstol por tierras de Jalisco tuvo lugar cuando el conquistador Nuño de Guzmán, fundador de Guadalajara, disfrutando hacia 1530 de los agasajos de la reina de Tonalá, fue atacado por varios miles de guerreros que llegaron a arrebatarle la lanza y darle una paliza, aunque el resultado de la batalla fue victorioso para los españoles, que la atribuyeron a la ayuda celestial de Santiago. A mediados del siglo XVIII los habitantes de la zona seguían rememorando la batalla:

Conservando la tradición de esta victoria que parece nuestra y que los indios tienen por suya -escribe el historiador Mota Padilla en 1740-. Inhiérese un indio en un caballo blanco formado de caña, que sujeta en la cintura, y armado con la encomienda de Santiago en una banderilla [...] con una espada en la mano, de madera dorada, al son de pífanos y atabales, finge batallar con otros indios vestidos a usanza de los gentiles antiguos, armados con sus chimales y macanas, y al acometerlos el fingido Santiago caen al suelo y vuelven a levantarse, repitiendo la escaramuza con donaires y celebridad, hasta que se le rinden ${ }^{29}$.

Ante una de las repetidas sublevaciones de los vecinos de Guadalajara, pocos años después, el Apóstol acudió en ayuda del conquistador Oñate, aplastando la rebelión; «este milagro representan cada año los indios en los pueblos de la [Nueva] Galicia» ${ }^{30}$. Es interesante mencionar una voz discordante en contra de estos atribuidos milagros del Apóstol, la del P. Frejes, franciscano natural de Guadalajara, quien expresó que:

\footnotetext{
A. Santoscoy, op. cit., pp. 23-30.

30 Ibidem, p. 36, cit. al P. Tello, Historia de la Nueva Galicia.
} 
No es la primera vez que estos bárbaros [los españoles de la conquista] levantan falsos y quimeras contra los santos, haciéndoles cómplices de sus maldades. ¿Qué tenía que hacer Santo Santiago con los infelices e inocentes indígenas que sólo se defendían de una agresión injusta? ¿Y cuándo fueron los indios a dominarlos, como los moros a ellos? [...] El mayor milagro que Dios y sus santos hicieron en la Conquista fue que los indios amaran tanto desde entonces una religión que los bárbaros españoles les trajeron en la punta de la espada y boca del cañón ${ }^{31}$.

Admitiendo una auténtica devoción colectiva hacia la figura simbólica de Santo Santiago, se puede analizar la estructura formal del ritual festivo de los Tastoanes en busca de las claves que favorezcan su interpretación.

1. El esquema argumental de estas representaciones está centrado en la secuencia: Persecución de Santiago - Captura por los tastoanes - Juicio y sentencia dictada por los Reyes - Muerte de Santiago - Resurrección de Santiago con potestad para sanar a los enfermos.

$\mathrm{Su}$ núcleo, Cautiverio-juicio-ejecución, corresponde a uno de los argumentos tradicionales de las mascaradas o farsas invernales en la Península Ibérica, y se aplica a peleles o fantoches con apariencia humana que terminan siendo pasto de las llamas purificadoras. Ejemplos de estas farsas carnavalescas son el Pero-Palo extremeño y el Miel-Otxin navarro, que se considera representan a unos malhechores que reciben castigo por sus maldades. En la farsa navarra, también participa un caballito fingido, que se enfrenta contra un estrafalario «hombre relleno de paja» y termina siendo herrado, mientras le protegen los «chachos», atemorizantes personajes enmascarados y tiznados, armados con palos, que se parecen a los tastoanes. Otros dos rituales con la misma secuencia narrativa son el de la manchega Fiesta del Sapo, donde al día siguiente de la batalla de Moros y Cristianos se captura, condena y mata al Sapo, fiera-monigote que simboliza la plaga de orugas; y el de la también navarra fiesta en la que siete cofrades de San Juan persiguen por el campo a un supuesto caudillo moro, llamado Juan Lobo, llevándolo atado sobre un caballo hasta la plaza en la que es juzgado y ejecutado a lanzadas en medio del escarnio general ${ }^{32}$.

Para lo que no encuentro conexiones con rituales peninsulares es para la última fase de la cadena secuencial, la «resurrección» de un Santiago tau-

31 Ibidem, p. 37, en la Memoria Histórica de los sucesos más notables de la conquista particular de Jalisco.

32 El Pero-Palo se representa en Villanueva de la Vera (Cáceres); el Miel-Otxin en Lanz (Navarra); el Sapo en Mota del Cuervo (Cuenca), en la Pascua de Pentecostés; y Juan Lobo en Torralba (Navarra), cada 24 de junio. 
matúrgico, dispensador de milagros ${ }^{33}$. Alguna luz nos puede dar la Fiesta de Santiago de Tequepexpan (Nayarit), cerca del límite de Jalisco. En la procesión patronal, un Niño-Ángel montado en un caballo blanco y con una espada y una cruz en las manos, encabeza la comitiva de «máscaros». Al término, el Ángel entrega cruz y espada a Santo Santiago, en el llamado «espaldarazo», para representar que Santiago es nombrado caballero al recibir tres golpes de espada en la espalda, mientras el Ángel le dice: «Santiago, Santiago / toma esta espada de acero / y con esta defenderás / al mundo entero». Santiago monta a caballo y se enfrenta en duelo singular contra cada uno de los máscaros o moros, que se rinden después de recibir varios golpes. Cuando todos han sido dominados, se forman en ejército a las órdenes de Santiago, «y van recorriendo el pueblo, buscando a la gente para darle tres cuerazos, a unos por devoción, como los bebés, y a otros por broma. La tarea es cuerear a todo el rancho. 'Medir las casas' es entrar a ellas para sacar a la gente a cuerearse» ${ }^{34}$. Aquí se vislumbra un lejano motivo inspirador del ritual, al tratarse de un fustigamiento colectivo, para alejar los males de la comunidad (que es 'medida' de modo semejante a como hacen los tastoanes), lo que de nuevo nos acerca a varios rituales invernales de la Península, en los que «enmascarados con látigos» golpean a todos los asistentes. Aunque aquí se deben conectar con personajes diabólicos, demoníaccos o ánimas vengativas.

En cuanto a la «resurrección del santo ejecutado», esta es la acción más característica de la liturgia de la Semana Santa, base sobre la que se fundamenta el cristianismo. $Y$ de nuevo en Nayarit, en varias comunidades coras se celebra la Semana Santa con algunos elementos muy singulares, que no se detectan en España.

Con la numerosa participación de hombres semidesnudos, tiznados y con dibujos de color blanco sobre la piel, llamados «la judea», se centra este ceremonial en la Danza de Judíos y Fariseos, de largo y complicado de-

33 Sin embargo, en la vertiente francesa de los Pirineos están registradas mascaradas carnavalescas en las que se mata a un personaje que luego resucita, como en las funciones suletinas estudiadas por Caro Baroja. En Arles-sur-Tech (Rosellón) en la invernal fiesta de la Candelaria se representaba la caza del oso que intentaba raptar a una doncella, y, tras ser perseguido y muerto de un disparo, resucitaba. Analizando los aspectos primitivos y eróticos de este ritual festivo, A. VAN GENNEP dice que son frecuentes «en el folklore internacional, la caza ritual, ejecutada por cazadores seleccionados, de un animal salvaje (que) primero muere, y luego, gracias a ciertos ritos y ciertos encantamientos, resucita anualmente» (Manuel de Folklore Français Contemporain, Paris, 1947, t. 1.o-III, p. 910). También hay algunos personajes de representaciones de Moros y Cristianos que gozan de la resurrección.

34 Encuesta a don Miguel Carrillo, 71 años, en agosto de 1990. 
sarrollo, cuyo significado sólo parecen conocer los jefes de las tribus coras. Comencemos por el Viernes Santo en la localidad de Jesús, María y José. Los judíos se han apoderado de las calles y se dedican a perseguir al niño que personifica al Nazareno, quien es ayudado por el Cirineo. Cuando son acorralados dentro de una casa, «la judea» les espera en dos filas en la calle, escapando los dos perseguidos entre medias de ellos, a los que simulan pegar, «éstos se postran, ante el ataque, y se revuelcan en el suelo lanzando terribles alaridos, golpeando los sables. Cuando el Nazareno ya va algo lejos, se levantan los judíos e inician otra vez la persecución. Este proceso se repite [...] hasta que la aprehensión se efectúa [...] amarran al niño Nazareno y lo conducen prisionero a la iglesia» ${ }^{35}$. Allí, el Centurión asalta el templo y ataca con su lanza al grupo escultórico del Santo Entierro. «Cumplida la simbolización de la muerte, los atacantes caen por tierra horrorizados de su acción.» Más tarde tiene lugar la procesión del Santo Entierro. Al día siguiente, Sábado Santo, en la Mesa del Nayar, el Centurión a caballo, con su capa negra y un sable, apoyado por el ejército de los «fariseos» (niños armados con arcos, flechas y sables), emprende la simulada matanza de los judíos: «Estos, después de mostrarse aterrados y chillar, se fingen muertos o huyen despavoridos» ${ }^{36}$. En la cercana Santa Teresa, también se produce el Sábado la pelea ritual entre los dos Centuriones (que hasta ese momento encabezaban la judea) contra la tropa de «pintos»o judíos, a quienes raspan los machetes con su sable, en señal de hacer declinar las armas. "Terminando este acto, los mencionados centuriones son perseguidos para tirarlos de sus caballos y forcejear con ellos» ${ }^{37}$.

Se puede conectar esta persecución del Niño-Dios por los «judíos» con la de Santiago por los «tastoanes», así como su prolongación en la que el personaje del Centurión se enfrenta a la «judea». Comparemos este esquema dramático con el de una zona geográfica muy distante, la isla filipina de Marinduque. Allí, el Domingo de Resurrección se representa una versión de la leyenda de Longinos, el centurión romano que clavó la lanza en el costado de Cristo, curado de la ceguera en un ojo al caerle una gota de la santa sangre y que, al convertirse por este milagro, fue ajusticiado por los fariseos. En el ritual filipino, Longinos cuenta su conversión, siendo inmediatamente perseguido por una cuadrilla de centuriones o «morions», capitaneada por Pilatos. Longinos es capturado y vuelve a escapar por tres veces, hasta que es muerto y llevado a enterrar mientras los «morions» le lloran afligidos. Es interesante notar que «los trajes y las máscaras de los "morions"

\footnotetext{
35 P. Castillo, op. cit., p. 235.

36 Ibidem, p. 225.

37 Ibidem, p. 242.
} 
que imitan fisonomías europeas de color rosado o rojo, con barbas negras y cascos romanos, se asemejan marcadamente a ciertos tipos mexicanos de Moros y Cristianos» ${ }^{38}$. Si en esta representación ritual de Semana Santa sustituimos el personaje de Longinos por el de Santiago, tendríamos un equivalente de las luchas Santiago-Pilatos y Santiago-tastoanes.

Para concluir con la Semana Santa, sólo conozco en la España contemporánea un caso de enfrentamiento ritual, aunque muy dulcificado: las «turbas» estrafalarias que con instrumentos musicales desafinados intentan impedir que la seria procesión de la madrugada del Viernes Santo en Cuenca avance, molestándola con sus insultos sonoros.

2. La acción del Sargento en alguno de los Tastoanes, de trazar rayas en el suelo con su espada, se puede relacionar con la que se ejecuta el Jueves Santo entre los coras de Ixcatán (Nayarit): Entran al pueblo una veintena de judíos o «tiznados», y al llegar a la calle principal:

trazan una gran raya transversal sobre la gruesa capa de tierra $[\ldots]$ con los sables de madera que portan [...] al final de la calle, marcan otra larga raya y mientras tanto hacen reverencias [...]. Después vuelven a la raya del principio de la calle, donde hacen otra ceremonia como la anterior. (Esto quizás sea en el fondo una adoración de la tierra) ${ }^{39}$.

Diferente interpretación de esta acción nos la ofrece Santoscoy: «Hay documentación histórica de que así se delimitaba el campo de batalla, o se marcaba el límite que conducía a la guerra» ${ }^{40}$.

3. Importancia simbólica del caballo:

Es sabido el impacto producido por la caballería española sobre los indígenas americanos, que pensaban que jinete y animal eran el mismo ser, una reminiscencia de lo cual se puede hallar en la citada creencia que hallé en Jocotán (Jalisco) de que «Santiago y el caballo son hermanos». Su importancia mítica es tal, que a menudo se nombra a Santiago como «el del caballo». Culminada la sangrienta conquista, a los indígenas se les prohibió la posesión de caballos, por lo que éstos también adquirieron una imagen de prestigio y estatus social.

En cuanto al uso festivo de los caballitos fingidos, es muy antiguo en la Península Ibérica. Ya un historiador musulmán del siglo XIV nos informa de la existencia de danzas con «bailarinas vestidas de muchachos, montadas

38 G. BEUTLER, op. cit., pp. 184-5: «En su forma actual este festejo, llamado ceremonia de Pugutan, fue instalado en la ciudad de Mogpog por el cura Pedro Santiago en 1807.» También se representa en la ciudad de Boac y en Gasan.

39 P. Castillo, op. cit., p. 244.

40 A. SANTOSCOY, op. cit., p. 23. 
en caballitos de madera [...] que simulaban verdaderos combates singulares» ${ }^{41}$. Un siglo después, para festejar su triunfal entrada en la conquistada Nápoles, el rey Alfonso $\mathrm{V}$ de Aragón fue obsequiado, entre otras diversiones, con la danza y batalla de los caballos fingidos contra una tropa de turcos a pie. La «pelea duraba un rato entre Moros y Cristianos», venciendo los catalanes y cautivando a los turcos que no lograron huir ${ }^{42}$. Muy populares luego como elemento de las procesiones del Corpus Christi, hoy día todavía salen en varias localidades del área catalana.

\section{CONSIDERACIONES FINALES}

Hasta aquí he expuesto los materiales encontrados sobre los enfrentamientos rituales de Santiago en España y México. La mayor diferencia se halla en que en los Tastoanes termina siendo vencido y muerto. Una explicación sugerente la ofrece el ya citado Santoscoy:

La raza indígena, cuyos individuos por una aberración que sólo se explica por el humillante estado en el que se coloca el ser oprimido, celebraban festivamente su propio vencimiento por el Apóstol Santiago [...] tergiversó la leyenda, convirtiendo a los vencidos en vencedores. Acaso entonces, el desenlace de la representación de los tastoanes, de ese modo cambiado, vino a tener para los indígenas nobilísimo significado, personificando en Santiago vencido el poderío español quebrantado por la independencia patria. La fiesta de los tastoanes vendría a ser la celebración de la conquista de la autonomía mexicana,

por lo que su origen es posterior a la independencia ${ }^{43}$. En el mismo sentido podemos situar algunas Danzas de la Conquista que terminan con el victorioso Moctezuma sometiendo a Hernán Cortés que, si bien es históricamente inexacto, en un ciclo de larga duración ya no lo es, puesto que los descendientes del mexica expulsaron de su tierra a las autoridades borbónicas.

Para ahondar más en el significado oculto de los Tastoanes puede ser útil elaborar un cuadro comparativo de oposiciones:

41 E. Lévi-Provençal, España Musulmana (tomo V de la Historia de España dirigida por Menéndez Pidal) (Madrid: Espasa-Calpe, 1957), p. 292, citando al historiador Ibn Jaldun, quien destacó la influencia que en su época ejercía la música española en todo el Norte de África.

42 Joan AMADES, Las danzas de moros y cristianos (Valencia: Diputación de Valencia, 1966), p. 101.

43 A. Santoscoy, op. cit., p. 40. 


\begin{tabular}{|c|c|c|}
\hline Localización & Vencedor-Vencido & Motivo del enfrentamiento \\
\hline México & Santiago-Pilatos & Conquista de Jerusalem \\
\hline Almolonga & Santiago-Pilatos & Rescatar la túnica de Cristo \\
\hline El Naranjo & Santiago-Infieles & Liberar las dos «Malinches» \\
\hline Chipalcingo & Santiago-Infieles & Liberar al Niño-Dios \\
\hline Tetelcingo & Santiago-Judíos & Liberar a Jesús \\
\hline Nayarit & Centurión-Judíos & Vengar la muerte de Cristo \\
\hline Tequepexpan & Santiago-Máscaros & $?$ \\
\hline Navarra & Cofrades-Juan Lobo & Castigar al malvado \\
\hline Filipinas & Morions-Longinos & Castigar la conversión \\
\hline Jalisco & Tastoanes-Santiago & $?$ \\
\hline
\end{tabular}

La primera apreciación es que los héroes son siempre vencedores salvo en dos casos: en Filipinas, donde el argumento de la representación se ajusta al Evangelio apócrifo que narra el suceso, y donde la pasión y muerte del buen centurión Longinos funciona como una réplica de la pasión y muerte de Cristo; y en los Tastoanes, donde a veces Santiago resucita para curar los males, gracias a sus nuevos poderes, y en otros casos simplemente revive. No está claro si en los rituales del siglo pasado también resucitaba el último día o si terminaban con su entierro.

En todo caso, es constatable la relación existente entre los Tastoanes y las representaciones de la Semana Santa hechas por los coras y, por lo menos, también por los mayos. Ya se mencionó antes la conexión en su estructura narrativa con los juicios de los peleles carnavalescos. En ellos, también se produce una ambivalencia respecto al protagonista, ya que es un enemigo de la moral al que se condena y ejecuta por sus excesos, estando a su favor los asistentes, pues el tiempo profano ofrece mayores posibilidades de placer y diversión que el tiempo sagrado. Y así como el disfrute sensorial era suprimido para los oprimidos durante la mayor parte del año, los símbolos de la alegría y la libertad eran ritualmente derrotados cada invierno. La similitud con las mascaradas carnavalescas queda patente en el disfraz y comportamiento de los tastoanes, maléficos y burlescos al mismo tiempo, atacantes del orden establecido.

Respecto a la danza de Santiago en sí, parece entroncarse con danzas guerreras precortesianas, con su modelo formal en las danzas de Santiago españolas, resultando casi idénticas la registrada en Jalisco en 1740 y la castellana de Cuenca de Campos, un siglo después.

Finalmente, al aislar los motivos de los enfrentamientos en estas representaciones rituales, encontramos varios de los que se repiten en las obras de Moros y Cristianos. La intervención de las Malinches parece ser una contaminación argumental con las Danzas de la Conquista. Y lo que resulta 
sorprendente es que en los Tastoanes y su cercana fiesta de los «máscaros» no se explicite el motivo por el cual Santiago debe luchar contra sus enemigos. Quizás se deba al propio discurso simbólico de este ritual, que recuerda la violenta oposición entre el caballero conquistador y los señores naturales, cuyos descendientes se vengan simbólicamente de la derrota al simular la muerte del invencible español. Pero, por un proceso de inversión, el caballero resucita como protector de la comunidad, como encarnación de una deidad con potestad sobre la guerra y la enfermedad, y que se coloca de parte de sus creyentes, mestizos en su gran mayoría. Así, como en la muerte del invierno que conmemoran las mascaradas carnavalescas, en esta mascarada ritual se «mata» la españolidad del Apóstol para beneficiarse de su poder sobrenatural.

Y terminaré con uno de los parlamentos que Tiberio, general y embajador de Pilatos, mantiene con Santiago en la Danza de Taxco:

Habla Tiberio: Parece que de esos cielos / toda la fuerza pelea.

¿Quién eres, bello español, / que me has dado tanta guerra?

$¿$ No sabes que soy Tiberio / y que alcanzo con mi ciencia

lo más difícil del mundo / y asombro de la tierra?

Pues los más duros peñascos / los derrumbo con mi fuerza; sólo a ti no he podido / tumbarte ya la cabeza.

Pues ya me tienes rendido, / dame la muerte apriesa.

¿Gran Señor, tanto penar! ${ }^{44}$.

DEMETRIO E. BRISSET

44 F. Horcasitas, op. cit., pp. 144-145. Esta danza, dedicada al Cristo Señor de Ojeda, se representaba los lunes y martes de Carnaval y el 2 de febrero, día de la Candelaria. 
La figura del Apóstol Santiago gozó de características emblemáticas tanto en la reconquista peninsular como en la conquista del Nuevo Mundo. Y el culto que se le rendía contenía elementos rituales con gran carga simbólica. Todavía en la actualidad es el santo más venerado en México, habiéndose transformado los rituales festivos que le dedicaban los españoles en otros que pueden ser tan enigmáticos como los tastoanes de Jalisco. Para interpretarlos, se someterá a un análisis histórico-formal el sistema de transformaciones constituido por los enfrentamientos rituales entre Santiago y sus diversos enemigos, y otras luchas de Semana Santa y carnaval, estructuralmente semejantes.

The figure of Saint James Apostle has enjoyed of emblematic characteristics so much in Peninsular reconquest as in the New World conquest. And the worship to him dedicated, includes ritual elements with an important simbolic charge. Still nowadays, he is the most venerated saint in Mexico, having been transformed the festive rituals to him dedicated by spaniards into others that can be so enigmatic as the Jalisco's tastoanes. In order to give an interpretation of them, I'll apply an historic-formal analysis to the transformations system established by ritual confrontations between Saint James and his different antagonists, an other, structuraly analogous, Holy Week and carnival fights. 